J. Management and Humanity Research

Vol. 3, 2020, 17-31

ISSN: 2582-7766 (online)

Published on 15 July 2020

www.researchmathsci.org

DOI: http://dx.doi.org/10.22457/jmhr.v03a03103

Journal of

\title{
Could Forming R\&D Alliance with Opportunistic Partners be Beneficial? Exploring the Proper Conditions
}

Tuhinur Rahman $^{1 *}$ and Mohammad Chowdhury ${ }^{2}$

${ }^{1}$ School of Management, University of Dhaka, Dhaka - 1212, Bangladesh.
${ }^{2}$ School of Economics and management, Dhaka International University
Dhaka - 1212, Bangladesh.
${ }^{*}$ Corresponding author: Tuhinur Rahman, E-mail: tuhinur.73@gmail.com

Received 10 May 2020; accepted 7 July 2020

Abstract. The purpose of this research is to evaluate whether it is beneficial to carry out $R \& D$ collaborations by partnering with an opportunist. We solve this problem by exploring the interactions between four key determinants in R\&D alliance, named opportunistic risks, knowledge spillovers, collaboration structures, and the performance of $R \& D$ alliance including private $R \& D$ investment and firm's final profits. By constructing a game model, we detect the impacts of opportunistic risks on R\&D performance, as well as the moderating role of knowledge spillovers and intensity of collaboration structures. Findings are the following two aspects. First, in opportunistic R\&D alliance, opportunistic risks play significant negative role on alliance performance by decreasing firm's private R\&D investment and the final profits. However, forming such alliance could still be beneficial as long as the knowledge spillover degree could be controlled within a proper scope (Under the model constructed in this paper, this critical vale is 0.5 and the effective interval is [0, 0.5]). This finding detects the basic condition to ensure opportunistic $\mathrm{R} \& \mathrm{D}$ alliance could create competitive advantage compared to noncooperation situation. Second, in opportunistic R\&D alliance, the positive effect, representing as increasing partner firm's private R\&D investment and final profits, can be enhanced through choosing intensive collaboration structures. And this finding proposes the strategy for improving opportunistic R\&D alliance's performance.

Keywords: R\&D alliance; collaboration structure; opportunistic risks; performance; knowledge spillover

\section{Introduction}

R\&D alliances have become very popular in these years. Prior studies have asserted that firms normally conduct R\&D collaborations with different partners simultaneously. The first studies of $R \& D$ alliances focus on the non-opportunism context with the main method of cooperative game. However, in these years, participants in R\&D alliance have been becoming more and more diversified. Some researchers also proposed the same idea. Tsang (1999) pointed out that inter-organizational collaborations could be differentiated into two types: competitive and non-competitive collaborations. A competitive collaboration is defined as the partners in a collaboration racing to learn. The 


\section{Tuhinur Rahman and Mohammad Chowdhury}

firm that learns fastest dominates the relationship and becomes a more formidable competitor via cooperation. On the other hand, for a noncompetitive collaboration, the partners are not direct competitors, or though the partners are direct competitors, they do not bring along the competitive mentality to the collaboration. The partners have no intention to compete in the same market in the foreseeable future but just enhance their skills and strengthen their positions in their respective markets. Tsang (1999) claimed that while the outcome of non-competitive collaborations is more likely to be a win-win situation, the outcome of competitive collaborations is often depicted as a win-lose situation. Is the claim really true? We doubt about it and carry out this research to explore the win-win conditions for competitive/opportunistic R\&D alliance.

We insist that when $R \& D$ alliance involves opportunistic partners (we call it opportunistic R\&D alliance in this paper), the relationship and interaction between partners will be very different from those under the traditional complete cooperation mode. The logic of opportunistic alliance is different from the traditional pure competition strategy or the pure cooperation strategy. The nature of opportunistic alliance is that there are both competition and cooperation simultaneously [1-2], just as the nature of co-opetition relationships. The goals of partners are only partially the same [3-4].

Opportunistic alliance is not a simple sum-up of competition logic and cooperation logic, but a combination of those two separated and paradox logics. Therefore, the governance of such kind of alliance is more complex than traditional competition or cooperation paradigm. It is obvious that the traditional competition paradigm analysis is based on the rule of maximization of private profits, and the traditional cooperation paradigm analysis is based on the principle of maximization of joint profits. However, in opportunistic alliance, the interests chased by partners are only partially the same. Thus, partners' decision criterion is not just private profit maximization or just joint profit maximization. Then the question comes out: How to depict the logic of simultaneous cooperation and competition?

Researchers have made some efforts to explore methods solving this problem by applying qualitative analysis, mathematical or economy methods, and empirical examinations. (1) Among the qualitative discussion papers, researchers discussed the existence of the two opposite strength in many kinds of opportunistic alliance relationships, the upside and the dark-side of opportunistic alliance, and the probably outcomes of such relationships [5-6]. (2) Among the mathematical or game models research, $R \& D$ cooperation between a set of symmetric or asymmetric opportunist firms has been examined by some authors in a repeated game framework [7-9]. In this type of model, opportunist firms are made to cooperate by implementing an implicit system of sanctions that result in a loss of reputation, or non-renewal of contracts, for any manifestation of opportunism. Studying the impact of spillovers on the stability of contracts in the context of such repeated games, the authors show that spillovers might have a positive or negative impact on the stability of R\&D cartels, depending on the nature and degree of spillovers relative to the nature and magnitude of product market competition. (3) Among the empirical studies, researchers examined the impacts of several variables (e.g. structure, trust, commitment, cheating, et al.) on the performance of partners in opportunistic alliances [11-14]. In these studies, opportunistic risks and collaboration structures are consistently stressed as key factors in the governance process, having great influence on final performance. On the aspect of opportunity risk, it is seen 


\section{Could Forming R\&D Alliance with Opportunistic Partners be Beneficial? Exploring the Proper Conditions}

as an inevitable outcome generated from the competition logic between partners. Das and Teng [15] point out that the opportunistic risk is specific to alliance, and they are decisive factors of alliance's performance. On the aspect of collaborative structure, Ring and Van de Ven [16] stress that the decision on structure mode is vital in the management of competitive alliance. Different structure means different cooperation depth and different interaction mechanism between partners, and finally will cause various performances. Furthermore, researchers also find that there are significant correlation between structure modes and opportunity risk degree. It means that opportunity risks could be controlled through choosing effective governance structures. In this paper, we will propose a method to depict the simultaneous competition and cooperation logic in a game model by introducing a particular parameter named co-opetition factor.

To formalize the logic of co-petition is only a part of this study and the final goal is to reveal the win-win conditions for opportunistic alliance. We will reach our research objective by exploring the mutual influencing mechanisms between opportunistic risks, collaboration structures, knowledge spillovers, and the performance in opportunistic $\mathrm{R} \& \mathrm{D}$ alliances. And the methodology used in this paper is game model. This research design is distinct to previous literatures significantly, especially in the following three aspects. First, expending the key variables and the mechanisms included in game models in alliance performance field. Among the extant studies making efforts on opportunistic alliance's performance based on game theory, although authors have proposed a dozen of factors which may play a role on performance, the most popular decisive factor is knowledge spillover. And the common research mode is detecting the bilateral relationships between each single factor and alliance's performance. This means there are huge research are working on the direct impacts of knowledge spillover on the R\&D alliance performance. In our paper, we will explore trilateral impacts between variables and thus detect more complex interactions and mechanisms. Second, very different from the game model researches, empirical studies in this field involve much more variables and test more relationships. And the focused factors in empirical studies are recognized as alliance structures and the level of opportunistic risks [17-20]. However, when taking a comprehensive view on existing literatures based on game method and empirical method, it is easy to see that key determinants are obviously isolated. In this paper, we will try to fill the gap by introducing some key variable commonly used in empirical studies into game models.

As to the specific contribution of this paper, the following two aspects should be referred. First, we make the first try of coping with alliance structures by a continuous variable in game model. In the existing literatures, the alliance structure is seen as a categorical variable measured by scales such as contracts, bilateral contracts, equity, joint ventures and so on. And the common research method doing research on alliance structures is empirical study or qualitative analysis. There has been little progress doing research on alliance structures by the tool of mathematical method or game models. Thus, the attempt in this paper is beneficial to expand the research method on the issue of alliance governance structures. Second, we detect the moderating role of knowledge spillovers in alliance, not just the direct effects on alliance performance like those in existing studies. Specifically, the influencing mechanism of structure choice and opportunistic risks on alliance performance under the moderating role of knowledge 
Tuhinur Rahman and Mohammad Chowdhury

spillover would be discovered. This research design can make contributions to enrich the research perspective on knowledge spillovers, and to reveal more complex mechanisms and interesting findings.

This paper is organized as follows. Section 1 proposes the question. Section 2 introduces the research variable and game background. Section 3 presents our models. Section 4 contains the results and five main findings. Section 5 concludes the paper. The research model of this paper could be shown as figure 1 .

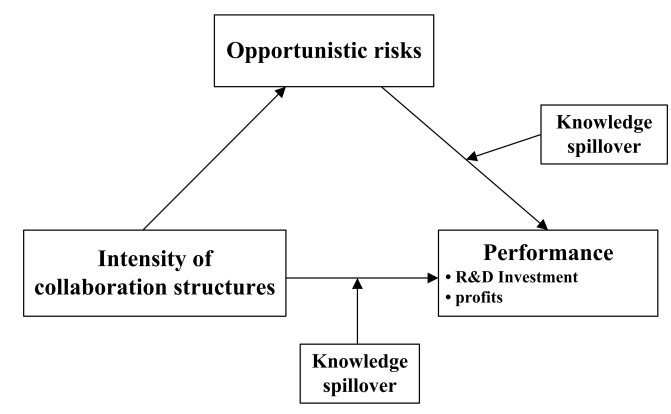

Figure 1: Research model

\section{Theoretical backgrounds and Basic variables}

\subsection{Collaboration structures}

Many researchers have made efforts on the issue of collaboration structures (others may call it governance formation). The most influential finding belongs to Das and Teng [15,17-20]. They classified collaboration structures into two typologies named equitybased structures and contract-based structures. The representative formations of equitybased structures include unilateral equity, bilateral equity, and joint venture. And the typical formations of contract-based structures include outsourcing, licensing, cross license, and so on. From the perspective of hierarchical degree, researchers rank those typical structures. For example, Santoro and McGill [21] distinguished five common collaboration structures as licensing, cross-licensing, bilateral alliance, minority equity alliance, and equity joint venture, ranking from the least hierarchical structure to the most hierarchical structure.

Shelanski and Clein [22] point out in their research that organization formations could be described by certain continuous variable. Based on their results, we hypothesis a continuous variable $l$ called governance intensity to represent the collaboration governance structures between partners in co-opetition relationship. The value of variable $l$ is positively proportional to the hierarchical degree of governance structures. Since high hierarchical degree is commonly related to intense interaction, thus variable $l$ could be used to describe the intensity of partners' interactions, including the frequency, the strength, and depth, and interactions like these.

\subsection{Knowledge spillovers}

R\&D spillovers refer to the involuntary leakage, as well as, the voluntary exchange of useful technological information.In this paper, we assume that after partners invest 


\section{Could Forming R\&D Alliance with Opportunistic Partners be Beneficial? Exploring the Proper Conditions}

resources to the alliance, partners could share those alliance resources and obtain a normal knowledge spillover degree. With this knowledge spillover, innovation activities can be carried out and new technologies or products could be created. In this paper, we use $\beta$ to denote the degree of knowledge spillover between partners. We make a hypothesis that the degree of knowledge spillover is determined by the feature of shared resource and it is independent to the intensity of alliance structures.

\subsection{Opportunistic risks}

Opportunism is defined as "self-interest seeking with guile. This includes but is scarcely limited to more blatant forms, such as lying, stealing, and cheating. ... More generally, opportunism refers to the incomplete or distorted disclosure of information, especially to calculated efforts to mislead, distort, disguise, obfuscate, or otherwise confuse" (Hill, 1990).

In this paper, we define opportunism as cheating on contracts to obtain extra knowledge spillovers from partners, e.g. accessing partner's private assets or skills which are not shared as alliance resource. We see an opportunistic partner as an agent who cheats whenever it is in his interest to do so. It is obvious that partnership in collaboration with opportunistic partner is significantly different from complete cooperation, since partners in complete cooperation never cheats and fully take their responsibilities written in the contract. Meanwhile, allying with opportunistic partner is also different from noncooperation, in which firms are completely independent, with no one contributes specific assets to others and no one can get any knowledge spillover.

We hypothesis an industry with two symmetric oligopoly firms $i$ and $j$. Each firm could be opportunistic or non-opportunistic. Under the situation of incomplete information, each firm only has information about their own type, but no definite information about other firm's type. Let $p(p \in[0,1])$ denotes the belief of any firm that its partner is an opportunist. Under the rule of tit-for-tat, firm $i$ makes its decision of whether to collaborate with firm $j$.

\subsection{Performance of $R \& D$ alliance}

There are controversial conclusions on performance of competitive R\&D collaborations. On the positive aspects, researchers (Inkpen 1996) proposed that collaborative R\&D alliances help partner firms to share knowledge and experience with each other. And there are abundant empirical studies investigating how inter-firm R\&D alliances help firms to improve their innovation performance (Harding 2001; Hemmert 2003; Muscio 2007). However, on the negative aspects, even more people insist that forming R\&D alliances with competing partners is a dangerous game. Partners will probably steal know-how and other core skill in order to enhance their own competencies. So in such "learning race", firms may lose much more than they obtain. Besides the underinvestment trouble (Sakakibara,2003;), a firm may even lose his relative competitive advantages. As a result, some researchers investigated the asymmetric partner performance (Lin, Yang \& Arya, 2009), and some other authors (Soekijad \&Andriessen, 2003) discussed the question of what kinds of knowledge could be shared with competing partners and what should not. 


\section{Tuhinur Rahman and Mohammad Chowdhury}

We hypothesized that firm $i$ and $j$ only carry collaboration in R\&D activities. They keep competition in production and marketing. During the cooperation, partners' common goal is to increase the amount of R\&D investment, which is beneficial for firms to reduce their production costs. Besides this common goal, each individual firm has its own private goal to increase his profit. Since there are two main goals in such R\&D alliance, it is reasonable to measure alliance's performance from those two perspectives. Thus, we will examine two kinds of performance. The first one is the amount of R\&D investment, measuring the common $R \& D$ performance. The second one is individual firm's final profit, measuring the private profit performance. Obviously, the scale of collaborative R\&D investment has decisive roles on each partner's final profits.

If partners both choose not to cooperate, then each of them will invest R\&D resources of $x_{\psi}^{n c}(\psi=i, j)$ and get the payoff of $\pi_{\psi}^{n c}(\psi=i, j)$. If they both choose to make collaboration and carry no opportunistic behavior, then each of them will invest R\&D resources of $x_{\psi}^{r}(\psi=i, j)$ and get the payoff of $\pi_{\psi}^{r}(\psi=i, j)$. If firm $i$ intends to cooperate with firm $j$ and firm $j$ is an opportunistic firm, then the investment of R\&D resource made by each firm is $x_{\psi}^{o p}(\psi=i, j)$ and the payoff is $\pi_{\psi}^{o p}(\psi=i, j)$.

\section{Models}

According to the Cournot game model, we set the inverse demand function as $P(Q)=a-Q$, where $p$ stands for the price of products, and $a$ stands for the basic demand. $Q=q_{i}+q_{j}$ is the total quantity, where $q_{i}$ and $q_{j}$ denote the quantity of firm $i$ and $j$, respectively. Further, let $c$ stands for the margin cost of firms. We set $a>c$ to make sure that there is meaningful market demand. Let us suppose that firms can reduce their costs of production through investment in $R \& D$. Let the R\&D expenditures of firm $i$ and $j$ be given by $x_{i}$ and $x_{j}$.

\subsection{Model for non-cooperation}

When firm $i$ and firm $j$ all choose non-cooperation strategy, there will be no alliance. Each firm chooses its own R\&D investment and decides the production quantity independently. The profit function of firm $i$ can be written as follows. Similar is the case for firm $j$.

$$
\max \pi_{i}^{n c}=\left[P(Q)-\left(c-x_{i}\right)\right] q_{i}-x_{i}^{2}
$$

We can solve the equilibrium of $R \& D$ investment and the final profits for each firm under non-cooperation condition as follows. Where $x^{n c}$ stands for the equilibrium R\&D investment for each firm, and $\pi^{n c}$ stands for each firm's equilibrium profit.

$$
\begin{aligned}
x^{n c} & =\frac{2}{7}(a-c) \\
\pi^{n c} & =\frac{5}{49}(a-c)^{2}
\end{aligned}
$$

\subsection{Model for complete cooperation}

If firm $i$ intends to form an alliance, then there will be two situations depending on the type of firm $j$. One is complete cooperation, and the other is opportunistic cooperation 


\section{Could Forming R\&D Alliance with Opportunistic Partners be Beneficial?}

Exploring the Proper Conditions

with an opportunist partner. Under the first condition, if the two firms are both nonopportunist, they will all respect the cooperation contracts and make decisions under the principle of joint profit maximization after they form alliance. During the process of $R \& D$ cooperation, there will be a knowledge spillover effect (to some non-negative extent under the given intellectual property regime), whereby the firms freely learn from the innovations or cost expenditures of other firms. Let $\beta$ from $(0,1)$ be the factor indicating the degree of spillover. Then from the spillover effect, each firm $i$ can experiences an additional reduction in costs equal to $\beta x_{j}$. Under this situation, the joint profit function of the alliance is as following.

$$
\max \left(\pi_{i}+\pi_{j}\right)=\sum_{m, n=i, j, m \neq n}\left[P(Q)-\left(c-x_{m}-\beta x_{n}\right)\right] q_{m}-x_{m}^{2}
$$

We can solve the equilibrium of R\&D investment and the final profits for each firm as follows. Where $x^{r}$ stands for the equilibrium R\&D investment for each firm under the situation of complete cooperation with no opportunistic partner, and $\pi^{r}$ stands for each firm's equilibrium of profit.

Further, since

$$
\begin{gathered}
x^{r}=\frac{(a-c)(1+\beta)}{9-(1+\beta)^{2}} \\
\pi^{r}=\frac{(a-c)^{2}}{9-(1+\beta)^{2}}
\end{gathered}
$$

$$
\frac{\pi^{r}}{\pi^{n c}}=\frac{49}{45-5(1+\beta)^{2}}>1
$$

We can see the profit under complete cooperation is higher than non-cooperation. This result demonstrates that returns under complete cooperation with no opportunistic motivation are absolutely superior to that under non-cooperation condition, regardless of the knowledge spillover degree.

\subsection{Model for cooperation with opportunistic partner}

When there is opportunist firm in alliance, each firm will make decisions about R\&D investments and products quantities based on the principle of maximizes its expected profit. We hypothesis the probability that firm $i$ thinks firm $j$ as an opportunist is given by $p(p \in[0,1])$. And thus the probability that firm $j$ is a totally cooperative firm is $1-p$. With this belief, each firm's decision function is as follows.

$$
\max \pi^{o p}=p \pi_{i}\left(x_{i}, x^{o p}\right)+(1-p) \pi_{i}\left(x_{i}, x^{r}\right)
$$

We can compute the respond functions of product quantity and the result of $R \& D$ investment for each firm as following.

$$
\begin{gathered}
q_{i}\left(x_{i}, x^{o p}\right)=\frac{1}{3}\left[a-c+(1+\beta) x^{o p}\right] \\
q_{i}\left(x_{i}, x^{r}\right)=\frac{1}{3}\left[a-c+(2-\beta) x^{o p}+(2 \beta-1) x^{r}\right] \\
x^{o p}=\frac{(a-c)(2-\beta)+(1-p)(2-\beta)(2 \beta-1) x^{r}}{9-p(1+\beta)(2-\beta)-(1-p)(2-\beta)^{2}}
\end{gathered}
$$




\section{Tuhinur Rahman and Mohammad Chowdhury}

where, $x^{o p}$ stands for the equilibrium R\&D investment for each firm when there is opportunist partner in alliance. $\pi^{o p}$ is the equilibrium profit for each firm. Since it is common that opportunist firm may have intentions to join in collaboration relationships only when the condition $\pi^{o p}-\pi^{n c}>0$ can be fulfilled. So we give a brief prove as follows to testify that $\pi^{o p}-\pi^{n c}>0$ is true.

In which

$$
\pi^{o p}-\pi^{n c}=\frac{D(a-c)^{2}}{49\left(5+2 p-5 p \beta+2 p \beta^{2}+4 \beta-\beta^{2}\right)^{2}(4+\beta)^{2}}
$$

$$
\begin{aligned}
D= & \left(-20 \beta^{6}-60 \beta^{5}+119 \beta^{4}+184 \beta^{3}-3477 \beta^{2}+3302 \beta-810\right) p^{2} \\
& +\left(20 \beta^{6}+30 \beta^{5}-40 \beta^{4}-104 \beta^{3}+4356 \beta^{2}+2704 \beta-2286\right) p \\
& -5 \beta^{6}+161 \beta^{4}+298 \beta^{3}-735 \beta^{2}-1750 \beta+3096
\end{aligned}
$$

Since

$$
\begin{aligned}
& -20 \beta^{6}-60 \beta^{5}+119 \beta^{4}+184 \beta^{3}-3477 \beta^{2}+3302 \beta-810 \\
& =-\left(\beta-\frac{1}{2}\right)^{2}\left(20 \beta^{4}+80 \beta^{3}-44 \beta^{2}-248 \beta+3240\right) \leq 0
\end{aligned}
$$

Thus, we can get the minimum value of $D$ at the extreme points when $p=0$ or $p=1$. Further, Since

$$
\begin{aligned}
& D(p=0)=-5 \beta^{6}+161 \beta^{4}+298 \beta^{3}-735 \beta^{2}-1750 \beta+3096>0 \\
& D(p=1)=\beta\left(-5 \beta^{5}-30 \beta^{4}-124 \beta^{3}-566 \beta^{2}+144 \beta+4256\right)>0
\end{aligned}
$$

Thus, it is easily to see $D>0$. Then, $\pi^{o p}-\pi^{n c}>0$ is true.

4. Influencing Mechanisms between collaboration structures, opportunistic risks, and performance

\subsection{The impact of collaboration structures on opportunistic risks}

According to transaction cost theory, organizational institutions have great influence on firm's opportunistic motivations. It means that whether a firm will implement opportunistic behavior significantly depends on what contracts it signs with its partner. Besides this theory, a number of empirical studies in strategic management field also get similar conclusions. Many researchers find out that there is significant influence between alliance structures and the opportunistic behaviors. For example, compared with contractbased structures, equity-based structures are more effective to decrease partner's opportunistic motivation. Based on these findings, it is reasonable to set the following proposition $p=p(l)$ and $\frac{\partial p}{\partial l} \leq 0$, where $p$ stands for the opportunistic motivation and $l$ is the intensity of collaboration structure, just as the definitions introduced in section 2 . The above function means that, along with the increasing of intensity of collaborative structures, the extent of opportunistic motivation of partner will be lowed down correspondingly, regardless of the degree of knowledge spillovers between partners.

\subsection{Impacts of opportunistic risks on alliance performance with the moderating role} of knowledge spillover

4.2.1. The impact of opportunistic risks on $R \& D$ investment performance

In this section, we try to explore the impacts of opportunistic risks $p$ on the R\&D investment which is seen as special asset investment in Transaction cost theory. In order 


\section{Could Forming R\&D Alliance with Opportunistic Partners be Beneficial?}

Exploring the Proper Conditions

to solve the question that whether it is reliable to increase R\&D investment through allying with an opportunist firm, we are going to compare the R\&D investment under conditions of non-cooperation and cooperation with an opportunist partner. Solve the partial derivative of $x^{o p}$ on $p$ in function (3), we can get:

$$
\frac{\partial x^{o p}}{\partial p}=\frac{-9(a-c)(2-\beta)(2 \beta-1)^{2}}{\left[9-(1+\beta)^{2}\right]\left\{9-p(1+\beta)(2-\beta)-(1-p)(2-\beta)^{2}\right\}^{2}} \leq 0
$$

Thus, we can obtain the following proposition 1 .

Proposition 1: The quantity of $R \& D$ investment is negatively related to the probability that partner is an opportunistic firm, regardless of the value of knowledge spillover.

Following proposition 1 , we can easily get

$$
x^{o p}(\beta, 1) \leq x^{o p}(\beta, 0)
$$

Since

$$
\frac{\partial x^{o p}(\beta, 1)}{\partial \beta}=\frac{(a-c)\left[(2-\beta)^{2}-9\right]}{[9-(1+\beta)(2-\beta)]^{2}}<0
$$

Thus, we can see that the minimum value of $x^{o p}$ under $p=1$ is $x^{o p}(1,1)$.

At this moment, we have

$$
x^{o p}(1,1)-x^{n c}=-\frac{1}{7}(1-c)<0
$$

This result reveals that when partner firm executes complete opportunistic behaviors, the minimum amount of R\&D investment invested by each firm will be so low that it is even less than the amount under non-cooperation situation. This will cause ineffective R\&D investment or call it under-invest.

Furthermore, since

$$
\frac{\partial x^{o p}(\beta, 0)}{\partial \beta}=\frac{(a-c)\left\{27(1+\beta)(2-\beta)-(2-\beta)^{2}[(1+\beta)(2-\beta)+9]-81\right\}}{\left[9 k-(1+\beta)^{2}\right]\left[9 k-(2-\beta)^{2}\right]^{2}}<0
$$

Thus, we can see that the maximal value of $x^{o p}$ under $p=0$ is $x^{o p}(0,0)$.

At this moment, we have

$$
\frac{x^{o p}(0,0)}{x^{n c}}=\frac{7}{5}\left(1-\frac{x^{r}}{a-c}\right)=\frac{49}{40}>1
$$

This result demonstrates that there exists an interval $V$ of $\beta$. When $\beta \in V$, we can obtain $x^{o p}(\beta, p) \geq x^{n c}$ 。 Thus we get the following proposition 2 .

Proposition 2: Even if there are opportunist partners in R\&D alliance, there still exists an effective interval $V$ of knowledge spillover degree $\beta$. When the condition that $\beta \in V$ is fulfilled, the amount of R\&D investment made by each firm in opportunistic R\&D alliance will overweight the amount happens under non-cooperation condition.

About the length of the interval $V$ of knowledge spillover $\beta$, it will be further explored in the following section when we analyze the impact of opportunistic risks on profit performance.

\subsubsection{The impact of opportunistic risks on profit performance}

We have 
Tuhinur Rahman and Mohammad Chowdhury

$$
\begin{aligned}
& \pi^{o p}=p \pi_{i}\left(x_{i}, x^{o p}\right)+(1-p) \pi_{i}\left(x_{i}, x^{r}\right) \\
& =p\left[q_{i}\left(x_{i}, x^{o p}\right)^{2}-\left(x^{o p}\right)^{2}\right]+(1-p)\left[q_{i}\left(x_{i}, x^{r}\right)^{2}-\left(x^{r}\right)^{2}\right]
\end{aligned}
$$

Solve the partial derivative of $\pi^{o p}$ on $p$. If we signify the result by $\frac{\partial \pi^{o p}}{\partial p}=\frac{B}{A}$, then the functions of $A$ and $B$ are as follows.

$$
\begin{aligned}
& A=\left(8-2 \beta-\beta^{2}\right)^{2}\left(5+4 \beta-\beta^{2}+2 p-5 p \beta+2 p \beta^{2}\right)^{3} \\
& B=9(a-c)^{2}(2 \beta-1)\left[-6 \beta^{5}-4 p \beta^{5}+30 \beta^{4}-2 p \beta^{4}-36 \beta^{3}\right] \\
& \left.+50 p \beta^{3}+30 \beta^{2}-40 p \beta^{2}-168 \beta-56 p \beta+32 p+216\right]
\end{aligned}
$$

In order to judge the sign of $A$ 、 $B$, we make the following mathematical deformation, setting two variables $M$ and $N$ to signify parts of $A$ and $B$, respectively.

$$
\begin{aligned}
M= & 5+4 \beta-\beta^{2}+2 p-5 p \beta+2 p \beta^{2} \\
N= & -6 \beta^{5}-4 p \beta^{5}+30 \beta^{4}-2 p \beta^{4}-36 \beta^{3}+50 p \beta^{3}+ \\
& 30 \beta^{2}-40 p \beta^{2}-168 \beta-56 p \beta+32 p+216
\end{aligned}
$$

(1) Since $M$ is a linear function of $p$, its maximum value is observed at the point of $p=0$ or $p=1$. It is easy to compute that $M_{0}=5+4 \beta-\beta^{2}>0$ when $p=0$, and $M_{1}=7-\beta+\beta^{2}>0$ when $p=1$. Thus, we can say $M>0$.

(2) Making a deformation on $N$ as follows in order to transform it to a linear function of $p$.

$$
\begin{aligned}
N= & \left(-4 \beta^{5}-2 \beta^{4}+50 \beta^{3}-40 \beta^{2}-56 \beta+32\right) p \\
& -6 \beta^{5}+30 \beta^{4}+36 \beta^{3}+30 \beta^{2}-168 \beta+216
\end{aligned}
$$

Thus, the maximum value of $N$ is generated at the point of $p=0$ or $p=1$ giving the value of $\beta$. It is easy to compute that $N_{0}=-6 \beta^{5}+30 \beta^{4}-36 \beta^{3}+30 \beta^{2}-168 \beta+216>0$ when $p=0$, and $N_{1}=-10 \beta^{5}+28 \beta^{4}+14 \beta^{3}-10 \beta^{2}-224 \beta+248>0$ when $p=1$.

Therefore, we can say $N>0$ is true. Thus, the sign of $\frac{\partial \pi^{o p}}{\partial p}$ is finally dependent on the sign of $2 \beta-1$. If so, we can have the following three results.

$\frac{\partial \pi^{o p}}{\partial p}<0$, when $\beta<\frac{1}{2}$

$\frac{\partial \pi^{o p}}{\partial p}=0$, when $\beta=\frac{1}{2}$

$\frac{\partial \pi^{o p}}{\partial p}>0$, when $\beta>\frac{1}{2}$

From the above three results, we can obtain the following proposition 3 .

Proposition 3: The decreasing of opportunistic risk could increase firm's profits when $\beta<\frac{1}{2}$. However, when $\beta>\frac{1}{2}$, the increasing of opportunistic risks would increase firm's profit (due to under-investment in R\&D). 


\section{Could Forming R\&D Alliance with Opportunistic Partners be Beneficial?} Exploring the Proper Conditions

This specific critical value of $\beta$ reveals the effective interval of $V$ we analyzed in the above part. It is easy to understand the first half conclusion, but it seems hard to understand the last half of the conclusion. The logic of the last half conclusion lies in that, when $\beta>\frac{1}{2}$, each firm's $R \& D$ investment made in opportunistic alliance will less than non-cooperation. This means that under-invest $R \& D$ expenditures will happen when $\beta>\frac{1}{2}$ in opportunistic alliance. At this moment, the knowledge spillover degree is not in the effective interval $V$. The under-invest of $\mathrm{R} \& \mathrm{D}$ expenditure reduces firm's total loss.

Comprehensively, the above proposition 1, 2 and 3 tell us that, when $\beta<\frac{1}{2}$, the $R \& D$ investment performance and the final profit performance will both keep increasing along with the decreasing of opportunistic risks. This means the optimal strategies for all partners are to choose non-opportunistic behavior and thus to get the largest win-win outcomes. In other words, the equilibrium strategy is (non-opportunistic, nonopportunistic). However, under the condition of $\beta>\frac{1}{2}$, firms both have incentive to behave opportunistically since $\frac{\partial \pi^{o p}}{\partial p}>0$. In this situation, the equilibrium strategy is (opportunistic, opportunistic), which means all partners will invest insufficient amount of $\mathrm{R} \& \mathrm{D}$ resources. This will prohibit the alliance from normal operation, and may cause disintegration. Thus, we can get the following conclusion 1:

Conclusion 1: Opportunistic R\&D alliance is only applicable when the knowledge spillover between partners is at a moderate or relatively low degree (in the model of this paper, the specific effective interval for knowledge spillover is [0, 0.5]). Only under this situation, forming R\&D alliance with opportunistic partners could benefit firms both in performance of $R \& D$ special investment and the performance of final profit. However, if the knowledge spillover exceeds the reasonable degree, ineffective R\&D investment will be generated and the alliance may probably face disintegration.

4.3. Impacts of collaboration structures on alliance performance with the moderating role of knowledge spillover

\subsubsection{The impact of collaboration structure on $R \& D$ investment performance}

Following function (3), we can get

$$
\frac{\partial x^{o p}}{\partial l}=\frac{\partial x^{o p}}{\partial p}-\frac{\partial p}{\partial l}
$$

Since we have proved that $\frac{\partial x^{o p}}{\partial p} \leq 0$ and $\frac{\partial p}{\partial l} \leq 0$, thus, we can observe the result of $\frac{\partial x^{o p}}{\partial l} \geq 0$. From this we can obtain the following proposition 4 . 


\section{Tuhinur Rahman and Mohammad Chowdhury}

Proposition 4. Under the condition of collaborating with an opportunistic partner, the amount of R\&D investment is positively with the intensity of collaboration structure, regardless of the value of knowledge spillover. Which means tighter collaboration structure can make contributions to encourage the investment of R\&D expenditures.

\subsubsection{The impact of collaboration structure on profit performance}

Since $\frac{\partial x^{o p}}{\partial l}=\frac{\partial \pi^{o p}}{\partial p}-\frac{\partial p}{\partial l}$, and $\frac{\partial p}{\partial l} \leq 0$, thus, we can know the sign of $\frac{\partial \pi^{o p}}{\partial l}$ is opposite from $\frac{\partial \pi^{o p}}{\partial p}$. Furthermore, because the sing of $\frac{\partial \pi^{o p}}{\partial p}$ is dependent on the sing of $2 \beta-1$, we can finally get the following results.

$$
\begin{aligned}
\frac{\partial \pi^{o p}}{\partial l}>0, \text { when } \beta & <\frac{1}{2} \\
\frac{\partial \pi^{o p}}{\partial l}=0, \text { when } \beta & =\frac{1}{2} \\
\frac{\partial \pi^{o p}}{\partial l} & <0, \text { when } \beta>\frac{1}{2}
\end{aligned}
$$

From the above three results, we can obtain the following proposition 5.

Proposition 5. Under the condition of allying with an opportunistic partner, firm's profit is positively with the intensity of collaboration structure when $\beta<\frac{1}{2}$. However, when $\beta>\frac{1}{2}$, firm's profit will be negatively with the intensity of collaboration structure.

Proposition 5 reveals that, in order to achieve high profit performance, R\&D alliance should choose some kind of tight structures when the knowledge spillover degree in alliance is low. However, if there are high spillover effects, then some kinds of loose relationships will be more appropriate. Based on the above proposition 4 and 5, we can obtain the following conclusion 2:

Conclusion 2: In opportunistic R\&D alliance, intensive collaboration structures are only applicable when the knowledge spillover between partners is at a relatively low degree (in the model of this paper, the specific effective interval for knowledge spillover is [0, $0.5]$ ). Only under this situation, applying intensive collaboration structures with opportunistic partners could benefit firms both in performance of $R \& D$ special investment and the performance of final profit. However, if the knowledge spillover exceeds the reasonable degree, ineffective $R \& D$ investment will be generated and the alliance may probably encounter disintegration.

\section{Conclusions}

In this paper, R\&D alliance with opportunistic partners was studied. Specifically, we explore the mutual influencing mechanisms between three variables known as alliance structures, opportunistic risks and alliance performance, as well as the moderating role of knowledge spillover in each relationship. In this paper, alliance performance includes two 


\section{Could Forming R\&D Alliance with Opportunistic Partners be Beneficial? Exploring the Proper Conditions}

measures named R\&D special investments and final profits. Research findings can be summarized as following.

On the first, regarding the relationship between alliance structures and opportunistic risks, theoretical analysis demonstrates that the relationship between intensive alliance structure and opportunistic risk level in alliance. This means that intensive collaboration structures are beneficial for reducing the probability that partners execute opportunistic behaviors, regardless the degree of knowledge spillover in alliance.

On the second, regarding the relationship between opportunistic risks and alliance performance, we find the opportunistic risks play negative role on alliance performance including having the potential to decrease the $R \& D$ special assets investment and the final profits. However, as long as the knowledge spillover degree could be controlled in a proper scope, forming alliance can still create win-win outcome which is superior to the situation of non-cooperation. Specifically, under the model constructed in this paper, the critical vale of knowledge spillover is $\frac{1}{2}$ and the corresponding effective interval is $\left[0, \frac{1}{2}\right]$. Both the R\&D special $R \& D$ investment and firm's final profits could be increased only when the degree of knowledge spillover belongs to this interval. And these positive effects could be intensified by increasing the intensity of collaboration structures. However, when the knowledge spillover degree exceeds the reasonable scope, insufficient R\&D investment will be generated and the alliance will face failure.

On the third, regarding the relationship between collaboration structures and alliance performance, we find that the intensive collaboration structures are only applicable when the knowledge spillover between partners is at a relatively low degree (in the model of this paper, the specific effective interval for knowledge spillover is [0, $0.5]$ ). Only under this situation, applying intensive collaboration structures with opportunistic partners could benefit firms both in performance of $R \& D$ special investment and the performance of final profit. However, if the knowledge spillover exceeds the reasonable degree, ineffective R\&D investment will be generated and the alliance may probably encounter disintegration.

Overall, findings in this paper comprehensively demonstrate that forming R\&D alliance with potential opportunistic partners is only meaningful when knowledge spillover is controlled lower than critical value (which is 0.5 in our model) and the collaboration structure is tight and intensive. Thus, firms should first evaluate the degree of knowledge spillover between his potential partner and himself before get involved into alliance. If the degree is relatively high, then it is better to avoid cooperation. Otherwise, if the knowledge spillover is in a moderate or low level, then cooperation could be executed and some kinds of strong ties should be chosen as alliance governance. In this way, the alliance could become an effective tool to enhance the R\&D investment and raise partners' revenues.

Acknowledgements. Thanks for the following funding projects: National natural science funding granted by NSFC (71202035), Postdoctoral funding granted by China 
Tuhinur Rahman and Mohammad Chowdhury

Postdoctoral Science Foundation (20110490803), and Humanities and Social Science funding granted by the Chinese Education Ministry (10YJC630125). Furthermore, thanks the China Scholarship Council for the support of further study in HEC Montreal in Canada, which creates opportunities for me to make deep discussions with my foreign tutor on this paper.

\section{REFERENCES}

1. R.Belderbos, M.Carree and B.Lokshin, Complementarity in R\&D cooperation strategies, Review of Industrial Organization, 28(4) (2006) 401-426.

2. C.A.Un, A.Cuervo-Cazurra and K.Asakawa, R\&D Collaborations and Product Innovation, Journal of Product Innovation Management, 27(5)(2010) 673-689.

3. E.W.K.Tsang, A preliminary typology of learning in international strategic alliances, Journal of World Business, 34(3) (1999) 211-229.

4. A.Parkhe, Interfirm diversity, organizational learning, and longevity in global strategic alliances, Journal of International Business Studies, 22(4) (1991) 579-601.

5. A.Muscio, The impact of absorptive capacity on SME's collaboration, Economics of Innovation \& New Technology, 16(8) (2007) 653-668.

6. A.Inkpen, Creating knowledge through collaboration, California Management Review, 39(1) (1996) 123-140.

7. R.Harding, Competition and collaboration in German technology transfer, Industrial and Corporate Change, 10(2) (2001) 389-418.

8. M.Hemmert, International organization of $R \& D$ and technology acquisition performance of high-tech business units, Management International Review, 43(4) (2003) 361-382.

9. C.W.L.Hill, Cooperation, opportunism, and the invisible hand: implications for transaction cost theory, Acadey of Mangement Review, 15(3) (1990) 500-513.

10. Z.Lin, H.B.Yang and B.Arya, Resource and complementarity and status association, Strategic Management Journal, 30(2009) 921-940.

11. M.Soekijad and E.Andriessen, Conditions for knowledge sharing in competitive alliance, European Management Journal, 21(5) (2003) 578-587.

12. M.Sakakibara, Knowledge sharing in cooperative research and development, Managerial and Decision Economics, 24(2/3) (2003) 117-132.

13. M.Bengtsson and S.Kock, Cooperation and competition in relationships between competitors in business networks, Journal of Business \& Industry Marketing, 14(3) (1999) 178-191.

14. M.Bengtsson and S.Kock, "Coopetition" in business networks - to cooperate and compete simultaneously, Industry Marketing Management, 29(2000) 411-426.

15. G.B.Dagnino and G.Padula, Co-opetition strategy: A new kind of interfirm dynamics for value creation, Paper presented at the EIASM Second Annual Conference, Stockholm, 9-11 May 2002.

16. C.H.Colin, L.Huaning and D.Barry, The paradox of co-operation and competition in strategic alliances: Towards a multi-paradigm approach, Management Research News, 26(1) (2003) 1-20.

17. M.Soekijad and E.Andriessen, Conditions for knowledge sharing in competitive alliances, European Management Journal, 21(5) (2003) 578-587. 
Could Forming R\&D Alliance with Opportunistic Partners be Beneficial?

Exploring the Proper Conditions

18. M.Zineldin, Co-opetition: the organization of the future, Marketing Intelligence \& Planning, 22(6/7) (2004) 780-789.

19. K.Kesteloot and R.Veugelers, Stable R\&D cooperation with spillovers, Journal of Economics \& Management Strategy, 4(1995) 651-672.

20. M.C.Dhersin and S.V.Ramani, Does trust matter for R\&D cooperation? A game theoretic examination, Theory and decision, 57(2004) 143-180.

21. B.S.Damiano and A.Weiss, Cooperation and competition in an R\&D market with spillovers, Research in Economics, 59(2005) 41-57.

22. A.Allan, How much do your "co-opetitors" capabilities matter in the face of technological change?, Strategic Management Journal, 21(3) (2000) 387-404.

23. T.Casciaro, Determinants of governance structure in alliances: The role of strategic, task and partner uncertainties, Industrial and Corporate Change, 12(6) (2003) 12231251.

24. H.Chen and T.J.Chen, Governance structures in strategic alliances: transaction cost versus resource-based perspective, Journal of World Business, (38) (2003) 1-14.

25. N.Arranz, and J.C.Fdez. de Arroyabe, Governance structures in R\&D networks: An analysis in the European context, Technological Forecasting \& Social Change, 74(2007) 645-662.

26. T.K.Das and B.S.Teng, Managing risks in strategic alliances, Academy of Management Executive, 13(4) (1999) 50-62.

27. P.S.Ring and A.H.Van de Ven, Structuring cooperative relationship between organizations, Strategic Management Journal, 13(1992) 483-498.

28. T.K.Das and B.S.Teng, Risk types and inter-firm alliance structures, Journal of International Business Studies, 26(1996) 91-116.

29. T.K.Das and B.S.Teng, Between trust and control: Developing confidence in partner cooperation in alliances, Academy of Management Review, 23(1998) 491-512.

30. T.K.Das and B.S.Teng, A resource-based theory of strategic alliances, Journal of Management, 26(1) (2000) 31-61.

31. T.K.Das and B.S.Teng, A risk perception model of alliance structuring, Journal of International Management, 7(2001) 1-29.

32. M.D.Santoro and J.P.McGill, The effect of uncertainty and asset co-specialization on governance in biotechnology alliances, Strategic Management Journal, 26(2005) 1261-1269.

33. H.A.Shelanski and P.G.Klein, Empirical research in transaction cost economics: A review and assessment, Journal of Law, Economics \& Organization, 11(2)(1995) 335-361. 